\title{
Compact and Circular Polarized RFID Antenna for Portable Terminal Applications
}

\author{
Yuan Yao, Youbo Zhang, Junsheng Yu, and Xiaodong Chen \\ School of Electronic Engineering, Beijing University of Posts and Telecommunications, Beijing 100876, China \\ Correspondence should be addressed to Yuan Yao; yaoy@bupt.edu.cn
}

Received 23 June 2013; Accepted 29 July 2013

Academic Editor: Chaowei Wang

Copyright (c) 2013 Yuan Yao et al. This is an open access article distributed under the Creative Commons Attribution License, which permits unrestricted use, distribution, and reproduction in any medium, provided the original work is properly cited.

\begin{abstract}
A novel compact and circular polarized antenna is proposed which can be easily fabricated and embedded into RFID readers. Circular polarization characteristic of the proposed antenna is achieved by introducing a crossed branch. The modified meandering line structure gives the antenna compactness characteristic. A prototype is fabricated and measured. The results show that this circular polarized antenna with compact dimension can cover the Chinese RFID operating band from $920 \mathrm{MHz}$ to $925 \mathrm{MHz}$, which make's the antenna suitable for handheld terminal application of RFID readers.
\end{abstract}

\section{Introduction}

In recent years, UHF RFID systems have moved from obscurity into mainstream applications due to some of their attractive features such as good reading ranges, high date rates, and potentially low cost [1-3]. An RFID system consists of reader, reader antenna, and tags. Since the tag antennas are linearly polarized, a circularly polarized RFID reader antenna is preferred to detect the random orientated tags [4-7]. In some applications, handheld or portable readers are required. And also RFID readers are now integrating with other portable terminal devices such as mobile phone. In these applications, the RFID reader antennas should be compact and easily integrated.

Monopole antennas [8-10] have been widely used in wireless communications with compact characteristic, good radiation patterns, simple structure, and easy integration with other devices, especially the meandering line structure, but they are usually used for linear polarization. Relatively very few designs are available in the open literature for achieving $\mathrm{CP}$ radiation using meandering line monopole structure.

In this paper, an antenna with compact and circular polarized characteristics for RFID reader application is proposed. The antenna covers the required bandwidths of RFID in China from $920 \mathrm{MHz}$ to $925 \mathrm{MHz}$. Monopole antenna with meandering line structure is designed to achieve compact characteristic, and cross loaded branches are used to achieve circular polarization. One distinguishing feature of the proposed antenna is that meandering line monopole antennas, which have been widely used in terminals and usually used for linear polarization, can achieve circular polarization radiation. Details of the antenna design are presented, and simulated and measured results are given to demonstrate the performance of the proposed antenna.

\section{Antenna Design}

Figure 1 shows the geometry of the proposed antenna. The antenna is mounted on FR4 substrate with permittivity of 4.4 and dielectric loss tangent of 0.02 and thickness of $1.6 \mathrm{~mm}$. Since the antenna is used in handset device, a palmsize test bench of $120 \mathrm{~mm}(L) * 60 \mathrm{~mm}(W) * 1.6 \mathrm{~mm}(h)$ is included to emulate the handset circuit board. A small antenna chip with the size of $50 \mathrm{~mm} * 6 \mathrm{~mm} * 1.6 \mathrm{~mm}$ is fabricated perpendicularly on the corner of the slab. In fact, most of the space is occupied by the test bench, so the space occupied by the antenna is relatively small.

The antenna is mainly composed of a rectangular ground with a rectangular clearance at the corner where the antenna chip is fabricated, a meander line, a feed line, a short line, and 

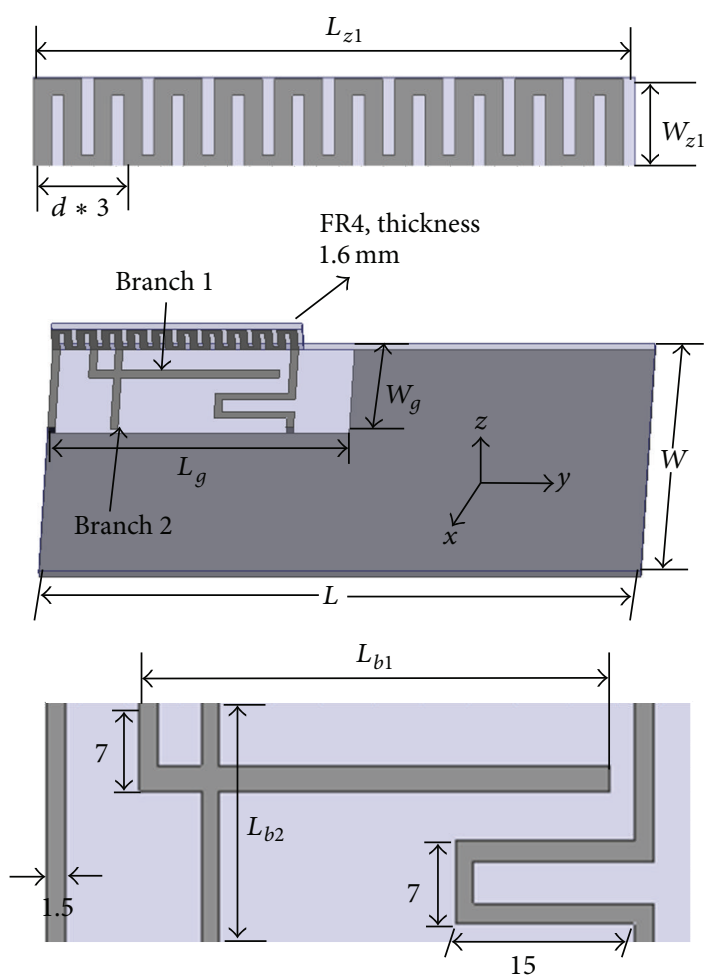

FIGURE 1: The geometry of the proposed antenna.

TABLE 1: Antenna dimensions.

\begin{tabular}{lccccc}
\hline Parameter & $L$ & $W$ & $L_{g}$ & $W_{g}$ & $L_{z 1}$ \\
\hline Value $(\mathrm{mm})$ & 120 & 67 & 60 & 22 & 50 \\
Parameter & $W_{z 1}$ & $L_{b 1}$ & $L_{b 2}$ & $d$ & \\
Value $(\mathrm{mm})$ & 6 & 35 & 18 & 2.5 & \\
\hline
\end{tabular}

a crossed branch. The meander line is printed on the small antenna chip, perpendicular to the test bench. The ground plane is printed on the back side of the slab while the feed line, crossed branch, and the short line are printed on the front side of the slab. The meander line and the crossed branch are fed by the feed line. In the fabricated prototype, a $50 \mathrm{Ohm}$ coaxial line is used to connect the antenna prototype and the test instrument.

Simulator Ansoft HFSS is used to simulate and optimize the proposed antenna design. Through numerous simulations, we can find that the impedance matching and AR bandwidth are primarily dependent on the meandering line structure and the cross shaped branch, separately. The crossed branch is a paramount factor and needs serious consideration in the AR of the designed frequency band. By carefully selecting the parameter of the cross, a broadband circular polarization is obtained. The finally chosen dimensions of the proposed antenna are illustrated in Table 1.

Figure 2 shows the radiation patterns of the proposed antenna at $920 \mathrm{MHz}$. From the results, we can see that the antenna has circular polarization characteristic. At one side, the antenna has left handed circular polarization (LHCP),

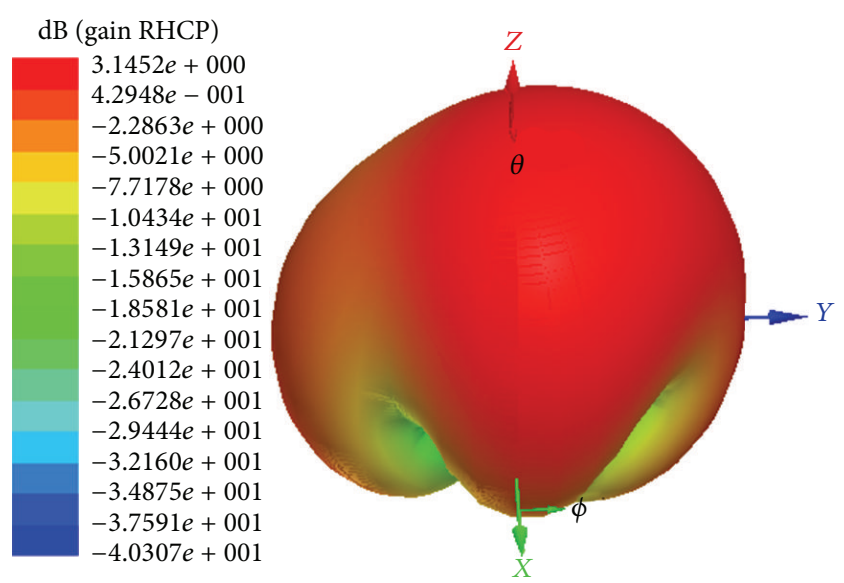

(a)
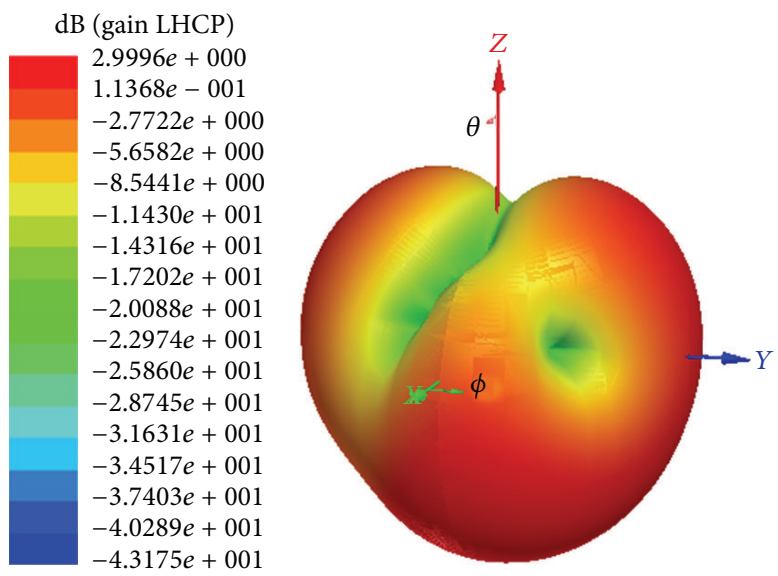

(b)

FIGURE 2: 3D radiation patterns of the proposed antenna. (a) RHCP pattern. (b) LHCP pattern.

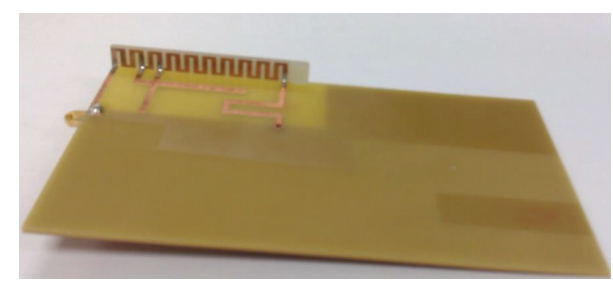

FIgUre 3: Photograph of the fabricated antenna.

and at the other side, the antenna has right-handed circular polarization (RHCP). It means that no matter the tags' orientation and position, the RFID reader antenna can identify them.

\section{Simulation and Measurement Results}

In order to verify the proposed antenna design, a prototype is fabricated as shown in Figure 3. All the measured results are carried out in anechoic chamber using VNA and other 


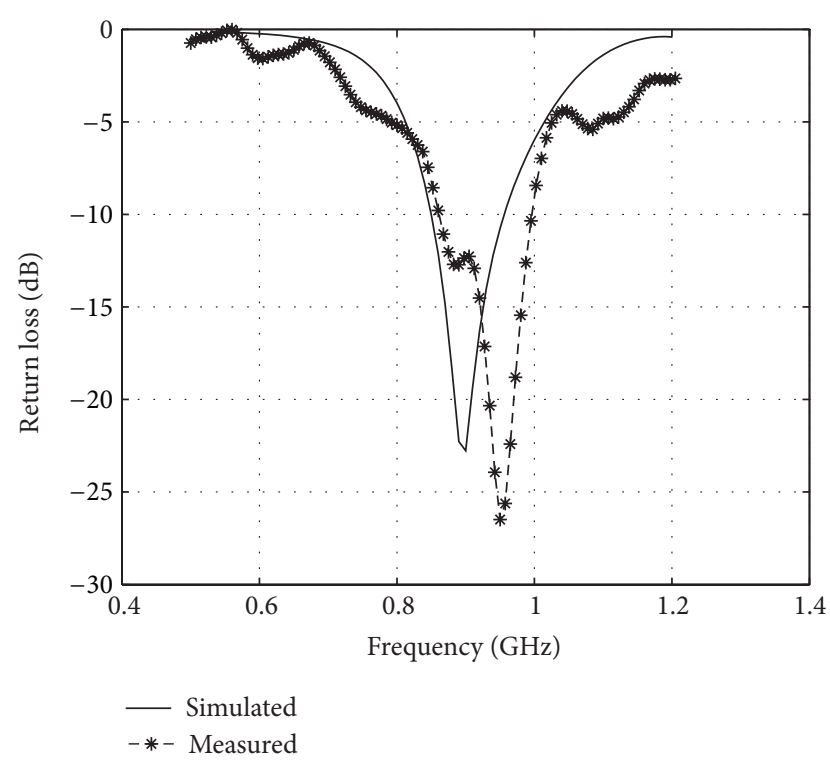

FIGURE 4: Simulated and measured S11 of the proposed antenna.

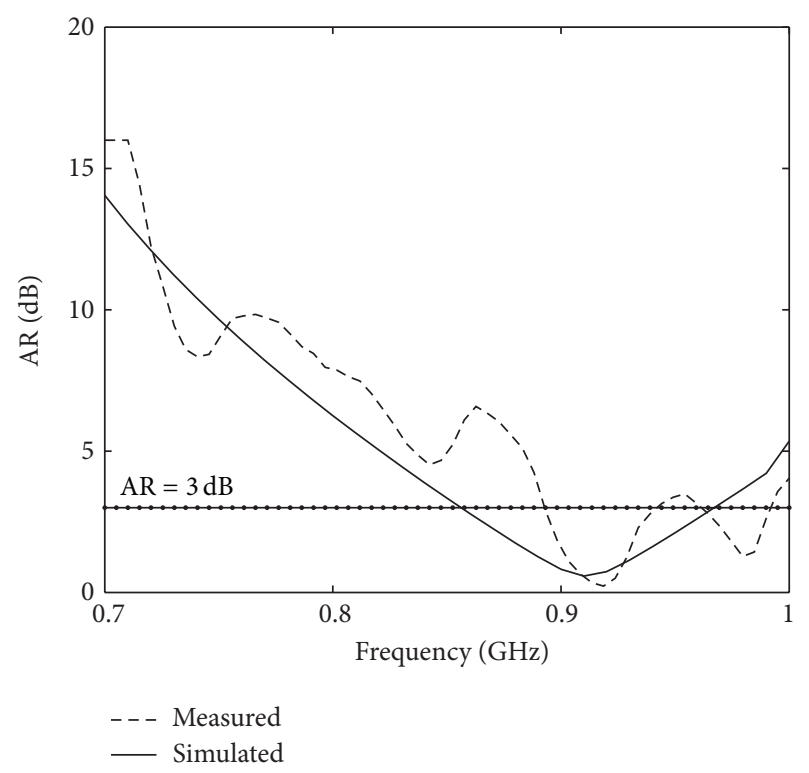

FIGURE 5: Simulated and measured axial ratio.

microwave test instruments. The simulated and measured reflection coefficients of the proposed antenna are shown in Figure 4. As can be seen, the proposed antenna has broadband impedance matching characteristic from $850 \mathrm{MHz}$ to $950 \mathrm{MHz}$ defined by $\mathrm{S} 11<-10 \mathrm{~dB}$, which covers most of the current RFID frequency bands.

Figure 5 shows the measured axial ratio in the broadside direction $\left(\theta=0^{\circ}\right)$. As can be seen, an AR bandwidth of around $50 \mathrm{MHz}$ from $890 \mathrm{MHz}$ to $940 \mathrm{MHz}$ for $\mathrm{AR} \leq 3 \mathrm{~dB}$ is shown, which means that the antenna achieves good circular polarization characteristic.
The simulated and measured $\mathrm{RHCP}$ radiation patterns of the antenna in $X-Z$ plane and $Y-Z$ plane at two different frequencies $920 \mathrm{MHz}$ and $925 \mathrm{MHz}$ are compared in Figure 6. The RHCP gain maximum, which is about $1.5 \mathrm{dBi}$, is found about 10 degree's away from $+Z$ direction, and the beam width defined by $>-3 \mathrm{dBi}$ is about 120 degree's at $920 \mathrm{MHz}$. The measured peak RHCP gain at $925 \mathrm{MHz}$ is about $2.0 \mathrm{dBi}$, and the beam width is about 100 degree's, narrower than the lower frequency which is caused by the higher peak gain. As can be seen, the antenna achieves good CP radiation patterns.

\section{Parameter Study}

For the purpose of optimized performance, parametric studies of the dimensions of the antenna structure are carried out. In this antenna design, the length of the crossed branches will have a big impact on the antenna performance, including the return loss and the axial ratio. In order to investigate the effects of the length of the crossed branch, we carried out a parameter study via HFSS. Figure 7 shows the simulated results of various branch 1 lengths $L_{b 1}$. From Figure 7(a), we can see that when $L_{b 1}$ changes from $34 \mathrm{~mm}$ to $37 \mathrm{~mm}$, the frequency of $\mathrm{S} 11<-10 \mathrm{~dB}$ goes down. The circular polarization characteristic will be also affected by the dimension of branch 1. As shown in Figure 7(b), when $L_{b 1}$ is changed from $34 \mathrm{~mm}$ to $37 \mathrm{~mm}$ the axial ratio turns worse. Taking into consideration both the return loss and axial ratio performance, we chose $L_{b 1}=35 \mathrm{~mm}$ as the optimized value in the final design.

In addition to branch 1 , the branch 2 dimension of the crossed branches is also a sensitive parameter to the antenna characteristics. Similar to $L_{b 1}$, we also sweep the branch 2 length $L_{b 2}$ from $18 \mathrm{~mm}$ to $22 \mathrm{~mm}$. Simulated results of different $L_{b 2}$ values are shown in Figure 8. Figure 8(a) shows that the working frequency goes down when $L_{b 2}$ varies from $18 \mathrm{~mm}$ to $22 \mathrm{~mm}$. Figure $8(\mathrm{~b})$ shows that the axial ratio remains unchanged when $L_{b 2}$ varies, which means that the circular polarization characteristic of the antenna is not sensitive to branch 2 dimension. So the selection of branch 2 length is mainly based on S11 results. We choose $L_{b 2}=21 \mathrm{~mm}$ as the final optimized value.

The meander line is an important part in the antenna design, so the internal's of the meander line $d$ is also a parameter that cannot be ignored. To study how the $d$ value affect's the antenna, several different values were used to simulate in HFSS. The results show that axial ratio is not sensitive to $d$ values, but the return loss of the antenna changed greatly while $d$ varies. Figure 9 shows the different results of S11 in terms of different $d$ values. From the figure we can see that while the value of $d$ goes up, the resonance frequency goes down. This can be obviously seen in terms of the rule longer current path lower resonant frequency. As the interval of the meander line becomes bigger, the total length of the current path get's longer, so the frequency reduce. 

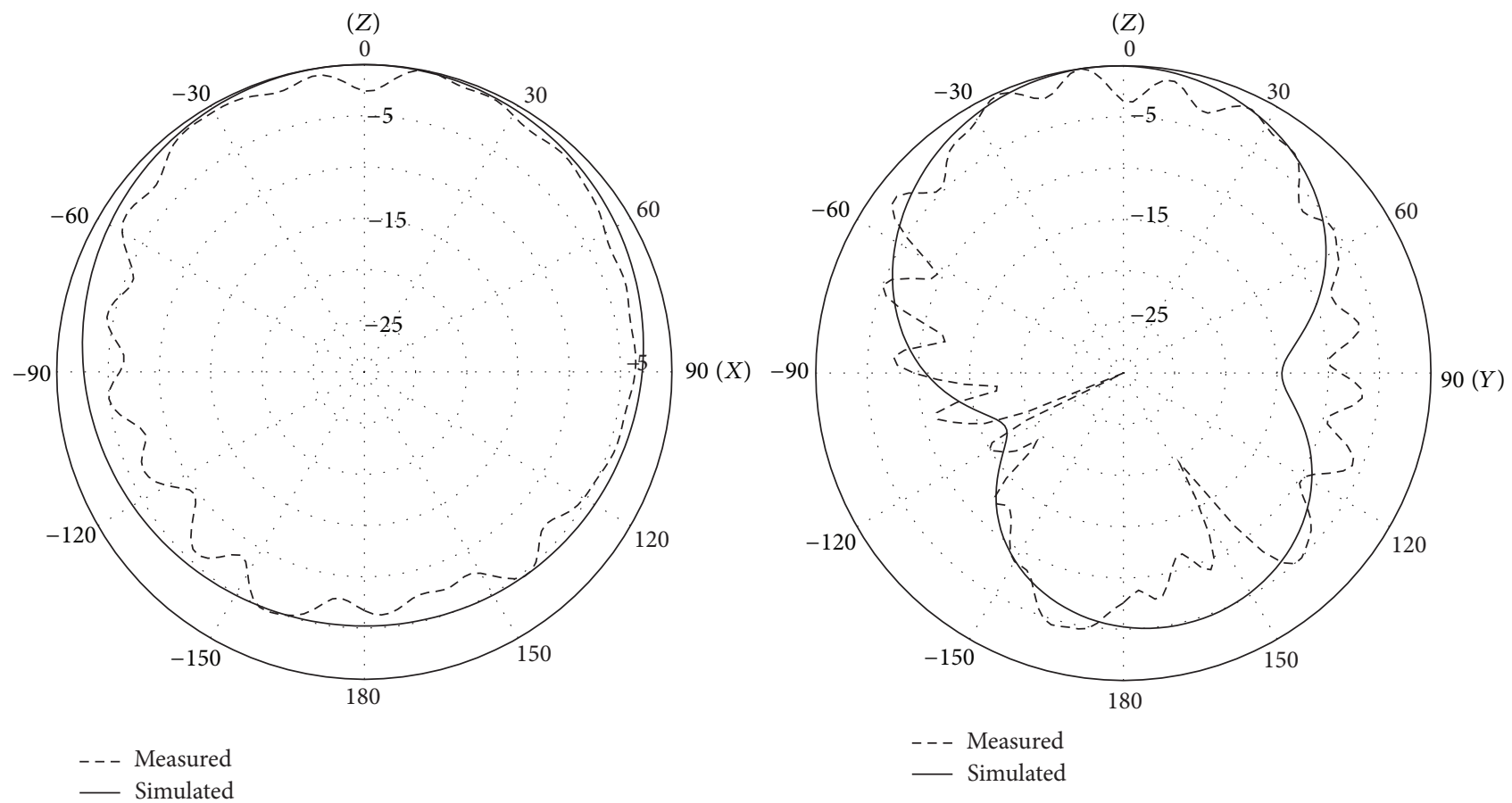

(a)
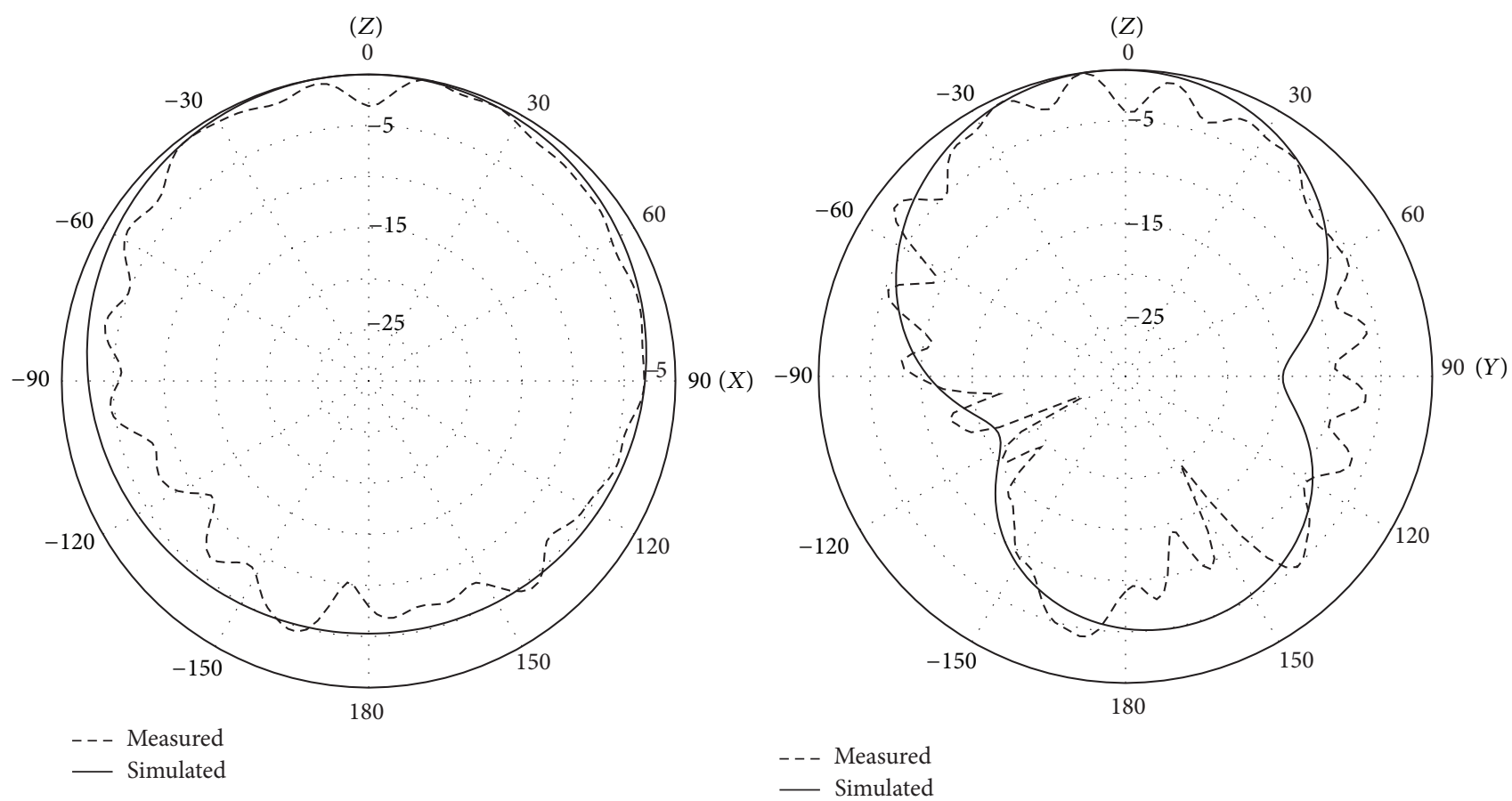

(b)

FIGURE 6: Simulated and measured radiation patterns at $920 \mathrm{MHz}$ and $925 \mathrm{MHz}$. (a) RHCP gain at $920 \mathrm{MHz}$. (b) RHCP gain at $925 \mathrm{MHz}$.

Finally, the dimension of the ground plane of the antenna is also a significant parameter that will have great impact on the antenna performance, including both return loss and axial ratio. So the parameter $L$ should be designed carefully in order to get a perfect antenna. Several values were tried in the simulation in order to get the appropriate length of $L$. The simulated results of return loss and axial ratio of different $L$ values are shown in Figure 10. Figure 10(a) shows that $L$ 


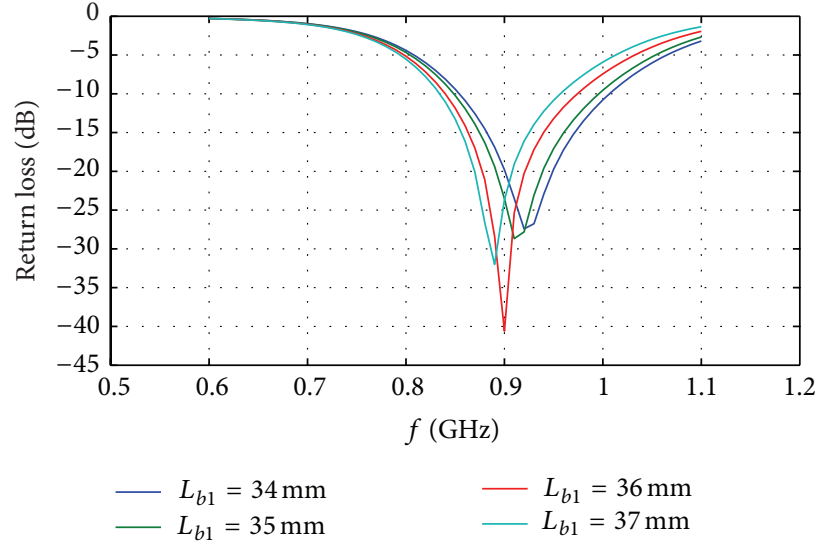

(a)

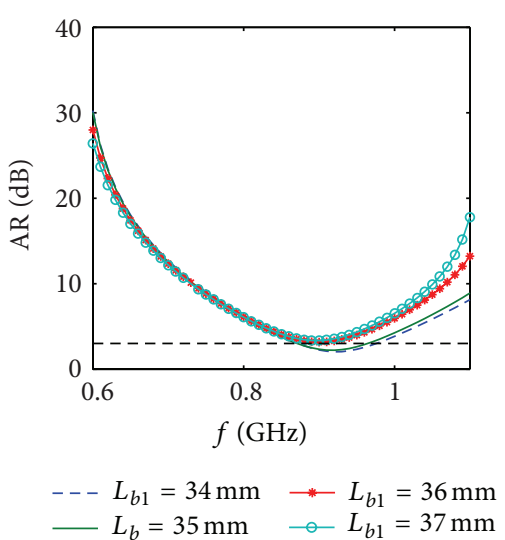

(b)

FIGURE 7: Comparison of S11 and AR of the antenna with different $L_{b 2}$. (a) S11. (b) Axial ratio.

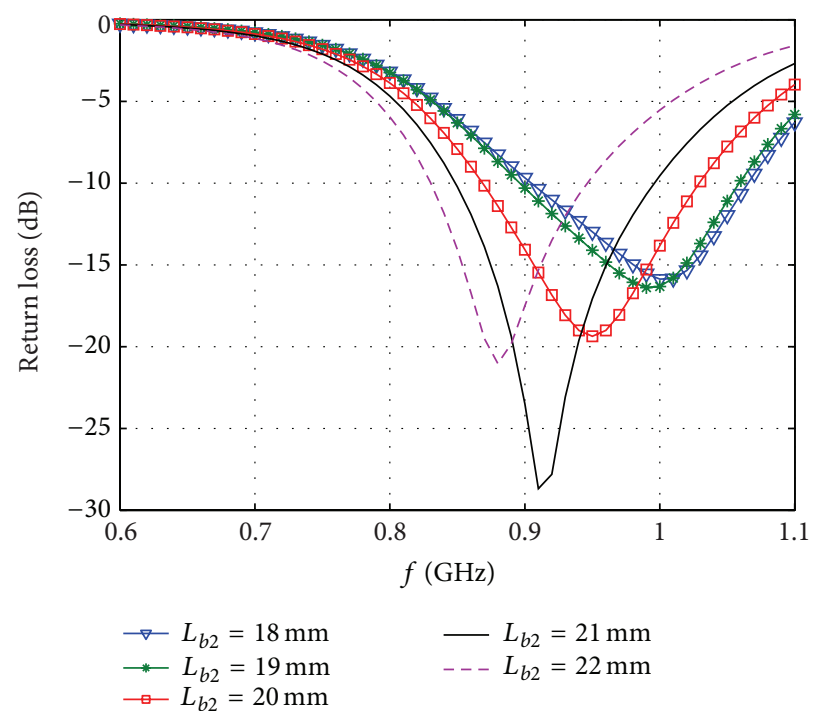

(a)

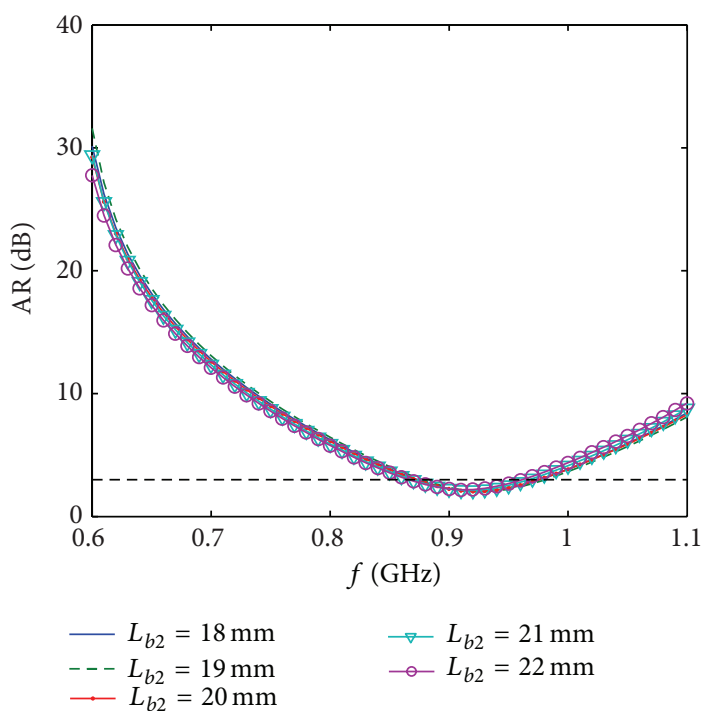

(b)

FIGURE 8: Comparison of S11 and AR of the antenna with different $L_{b 2}$. (a) S11. (b) Axial ratio.

mainly affects the impedance bandwidth. Figure 10(b) shows that the frequency of $\mathrm{AR}<3 \mathrm{~dB}$ will shift when $L$ varies. While $L$ changes from $100 \mathrm{~mm}$ to $150 \mathrm{~mm}$, the frequency of $\mathrm{AR}<3 \mathrm{~dB}$ goes down quickly. Taking into account the S11, AR performance, and fabrication considerations, $L=120 \mathrm{~mm}$ is finally chosen as the optimized value in the antenn design.

In addition to the parameters mentioned above, the dimensions of the clearance at the corner of the ground plane also affect the resonance frequency slightly. So the parameters $W_{g}$ and $L_{g}$ should be designed carefully to get good impedance match.

From the analysis above, we can conclude that the axial ratio is mainly affected by the branch 1 length and ground length and all the dimensions of the antenna part have effects on the return loss characteristic.

\section{Conclusion}

In this paper, a design of compact and circular polarized RFID reader antennae for portable terminal applications is proposed. The antenna has the compactness and circularly polarization at the same time by introducing the meandering line structure and crossed branch. Both simulation and measurement results show that the return loss and AR cover the whole Chinese RFID frequency band. This antenna could find its application in handheld terminals for mobile RFID reader system. 


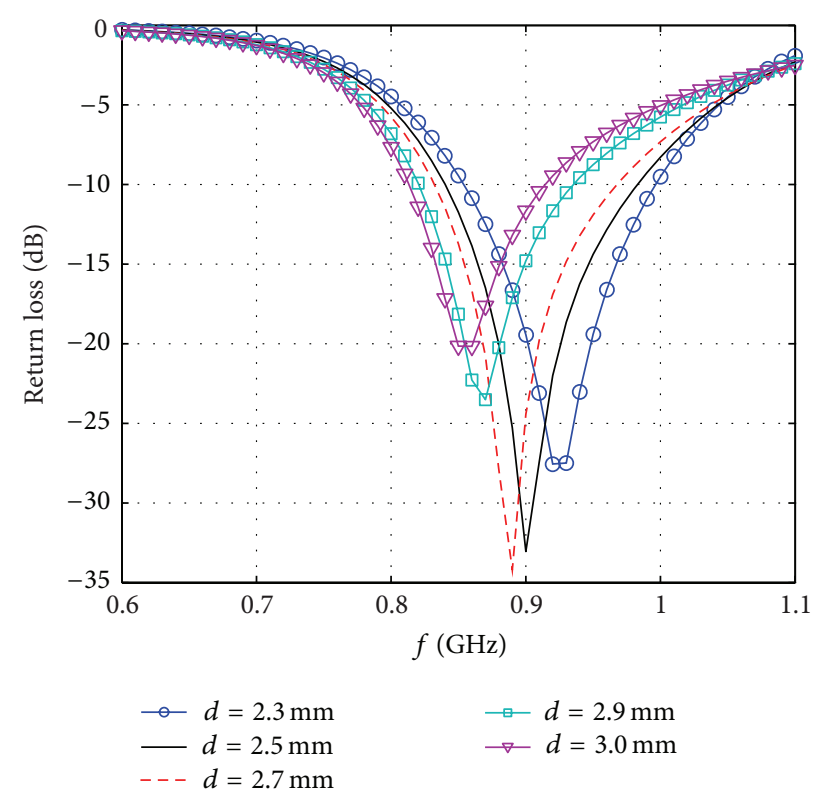

Figure 9: Comparison of S11 of the antenna with different $d$.

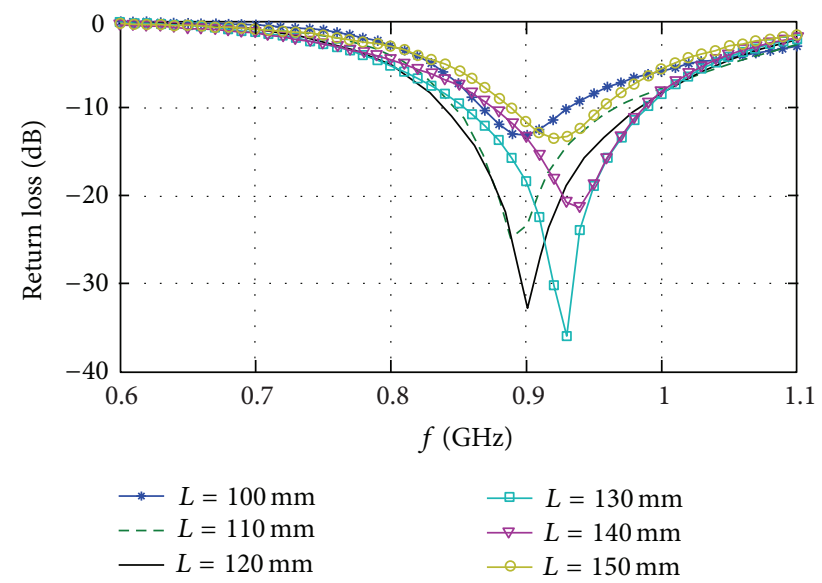

(a)

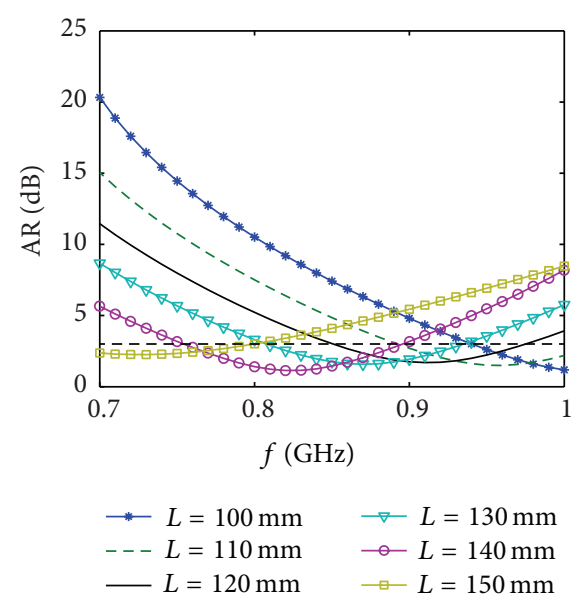

(b)

FIgURE 10: Comparison of S11 and AR of the antenna with different L. (a) S11. (b) Axial ratio.

\section{Acknowledgments}

This work is supported by the Fundamental Research Funds for the Central Universities, the National Natural Science Foundation of China under Grant no. 61201026, and the Beijing Natural Science Foundation (4133091).

\section{References}

[1] Y. Yao, Y. Sui, X. Chen, and J. Yu, "Planar antenna for RFID tags on metal platform," in Proceedings of the International Workshop on Antenna Technology: Small Antennas, Novel Structures and Innovative Metamaterials (iWAT '11), pp. 408-411, March 2011.

[2] X. Qing, C. K. Goh, and Z. N. Chen, "A broadband uhf near-field rfid antenna," IEEE Transactions on Antennas and Propagation, vol. 58, no. 12, pp. 3829-3838, 2010.

[3] G. Marrocco, "The art of UHF RFID antenna design: impedance-matching and size-reduction techniques," IEEE Antennas and Propagation Magazine, vol. 50, no. 1, pp. 66-79, 2008.

[4] S.-H. Jeong and H.-W. Son, "UHF RFID tag antenna for embedded use in a concrete floor," IEEE Antennas and Wireless Propagation Letters, vol. 10, pp. 1158-1161, 2011.

[5] P. V. Nikitin and K. V. S. Rao, "Helical antenna for handheld UHF RFID reader," in Proceedings of the 4th Annual IEEE International Conference on RFID (RFID '10), pp. 166-173, April 2010.

[6] N. Nasimuddin, Z. N. Chen, and X. Qing, "Asymmetric-circular shaped slotted microstrip antennas for circular polarization and RFID applications," IEEE Transactions on Antennas and Propagation, vol. 58, no. 12, pp. 3821-3828, 2010.

[7] Z. N. Chen, X. Qing, and H. L. Chung, "A universal UHF RFID reader antenna," IEEE Transactions on Microwave Theory and Techniques, vol. 57, no. 5, pp. 1275-1282, 2009.

[8] Y. Yao, J. Yu, and X. Chen, "Compact multi-band planar antenna design," in Proceedings of the Asia-Pacific Microwave Conference, pp. 1328-1330, 2012.

[9] J. Lu and Y. Wang, "Internal uniplanar antenna for LTE/GSM/ UMTS operation in a tablet computer," IEEE Transactions on Antennas and Propagation, vol. 61, no. 5, pp. 2841-2846, 2013.

[10] W. Chen and W. Jhang, "A planar WWAN/LTE antenna for portable devices," IEEE Antennas and Wireless Propagation Letters, vol. 12, pp. 19-22, 2013. 

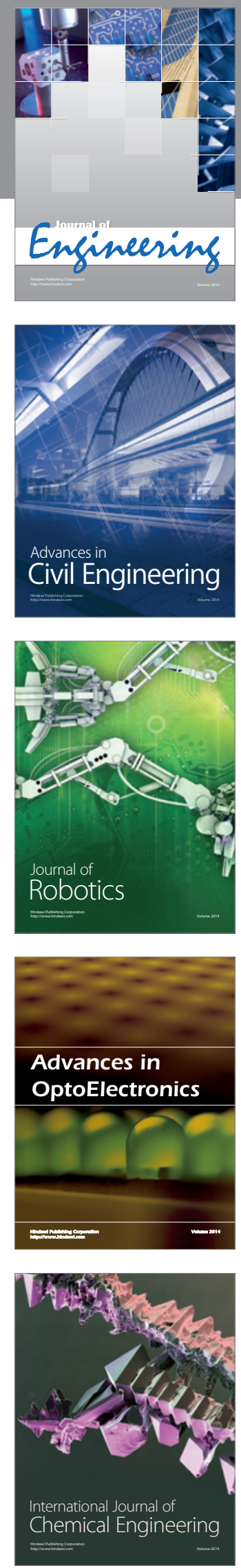

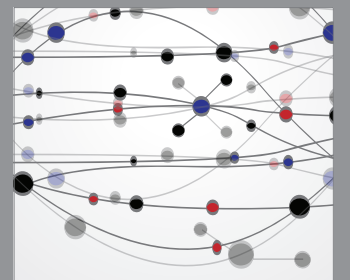

The Scientific World Journal
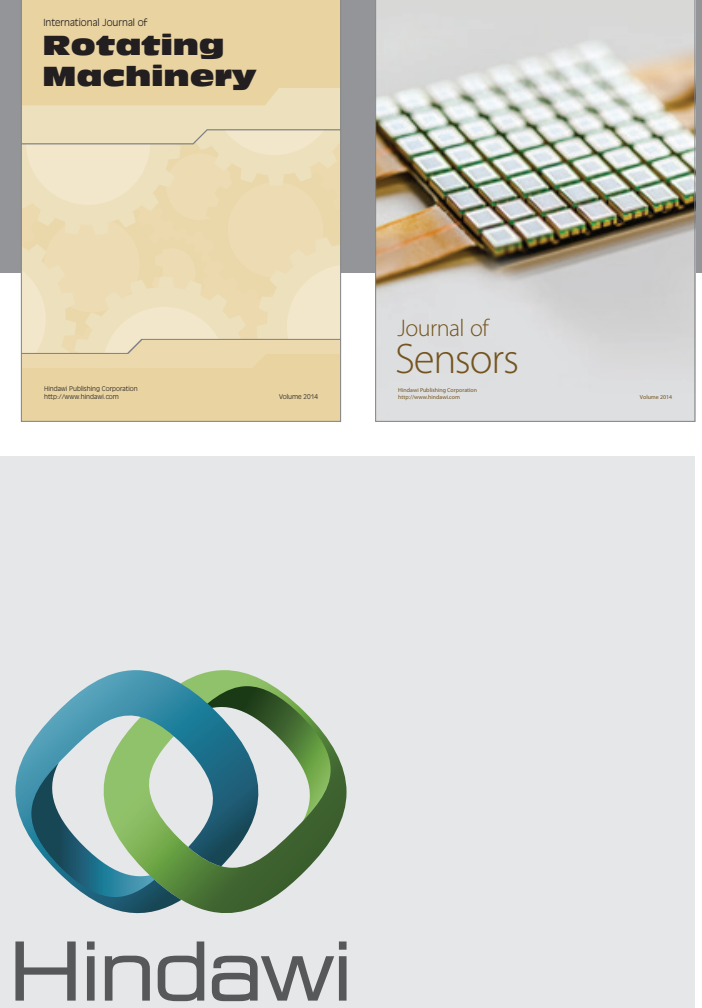

Submit your manuscripts at http://www.hindawi.com
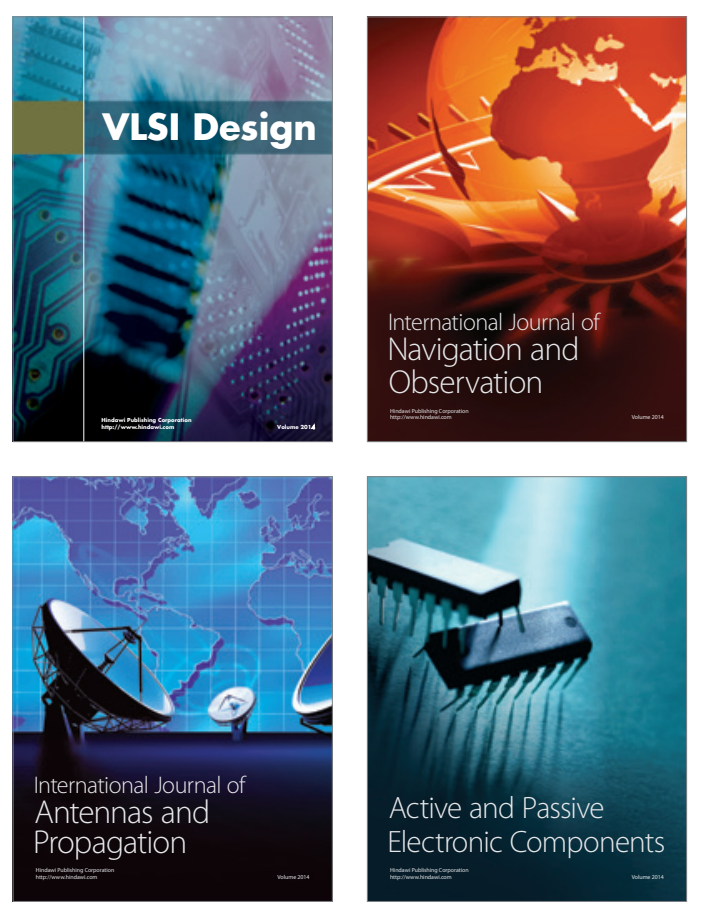
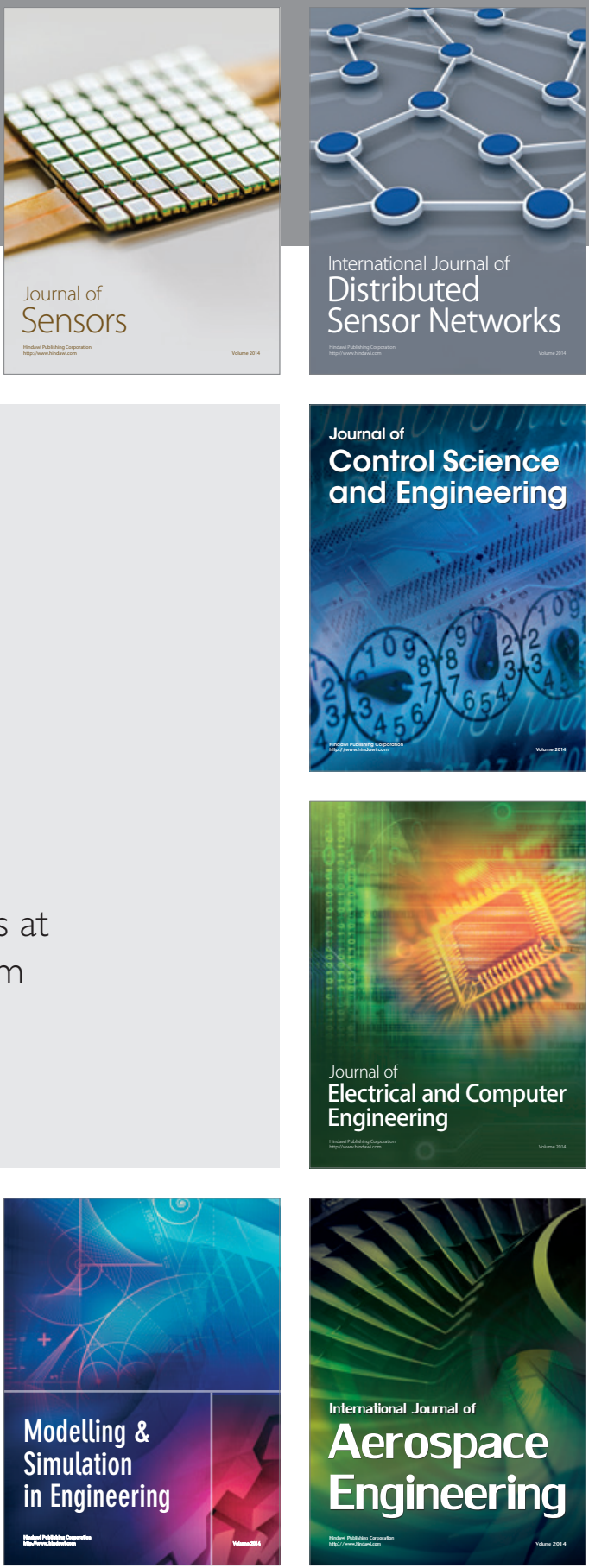

Journal of

Control Science

and Engineering
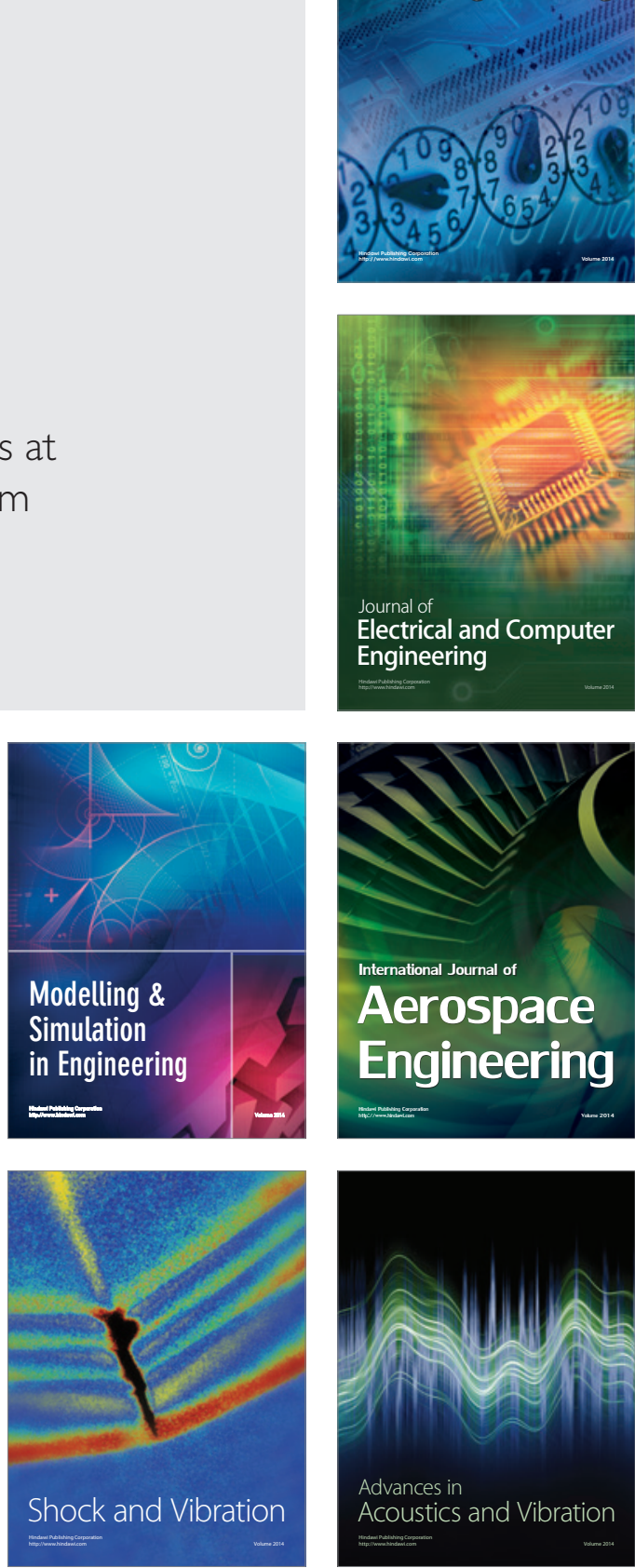